\title{
Mechanical thrombectomy for pediatric stroke arising from an atrial myxoma: case report
}

\author{
Rafael A. Vega, MD, PhD, ${ }^{1}$ Julie L. Chan, BS, ${ }^{1}$ Tony I. Anene-Maidoh, MD,1 \\ Margaret M. Grimes, MD, ${ }^{2}$ and John F. Reavey-Cantwell, MD, MS ${ }^{1}$ \\ Departments of ${ }^{1}$ Neurosurgery and ${ }^{2}$ Pathology, Children's Hospital of Richmond, Virginia Commonwealth University, Richmond, \\ Virginia
}

\begin{abstract}
Children experiencing severe neurological deficit due to acute ischemic stroke may benefit from endovascular intervention. The authors describe the use of mechanical thrombectomy in the treatment of embolic occlusion secondary to an atrial myxoma in a pediatric patient. This case involved an 11-year-old boy with a history notable for Raynaud syndrome and a distal extremity rash who presented to the emergency department with dense hemiparesis secondary to thromboembolic occlusion of the $M_{1}$ segment of the middle cerebral artery. Following mechanical thrombectomy, the patient's pediatric National Institutes of Health Stroke Scale score improved from a 16 to a 7 . In the setting of acute pediatric stroke due to atrial myxoma emboli, mechanical thrombectomy may be a first-line therapy.
\end{abstract}

http://thejns.org/doi/abs/10.3171/2014.10.PEDS14292

KEY WORDS atrial myxoma; cerebral emboli; mechanical thrombectomy; pediatric stroke; vascular disorders

$\mathrm{P}$ EDIATRIC stroke is an uncommon occurrence, with an estimated incidence of $2.3-13$ per 100,000 children. ${ }^{13}$ Although rare, the incidence appears to be rising. Acute ischemic stroke (AIS) is associated with significant morbidity and mortality; up to $50 \%-80 \%$ of survivors have neurological deficits, most commonly hemiparesis, but also long-term neuropsychiatric and behavioral issues. ${ }^{4}$ The etiology of AIS in the pediatric population differs from that in adults because pediatric stroke is often related to congenital disease or trauma as opposed to acquired cardiovascular complications. ${ }^{5}$ Cardiac myxoma is the most common primary heart tumor and is a benign neoplasm of endocardial origin. The location is usually in the left atrium. Atrial myxomas can be associated with a syncopal episode or sudden death as well as embolization resulting from tumor dislodgment or thrombus formation that can lead to AIS. ${ }^{12}$ These lesions usually have an insidious presentation and the diagnosis is rarely known before or at the onset of stroke. We report an unusual case in which mechanical thrombectomy was used in the suc- cessful treatment of AIS secondary to a pediatric atrial myxoma.

\section{Case Report \\ History and Examination}

An 11-year-old boy with a medical history notable for Raynaud syndrome and recurrent rash on both feet was brought to the pediatric emergency room 1 hour and 15 minutes after a syncopal episode during soccer. Following his initial collapse, the patient developed acute-onset dense left-sided hemiparesis, facial droop, right gaze deviation, and dysarthria. On examination his initial pediatric National Institutes of Health Stroke Scale (NIHSS) score was 16 , and inspection of the extremities revealed multiple blanching lesions across his feet bilaterally (Fig. 1). Subsequent imaging including head $\mathrm{CT}$ and $\mathrm{CT}$ angiography demonstrated early evidence of hypodense changes in the right hemisphere (Fig. 2 left) and complete occlusion of the proximal $\mathrm{M}_{1}$ segment of the right middle cerebral ar-

ABBREVIATIONS AIS = acute ischemic stroke; $\mathrm{AP}=$ anteroposterior; $\mathrm{IV}=$ intravenous; $\mathrm{MCA}=$ middle cerebral artery; NIHSS = National Institutes of Health Stroke Scale; $\mathrm{PCOA}=$ posterior communicating artery; r-tPA = recombinant tissue plasminogen activator.

SUBMITTED June 24, 2014. ACCEPTED October 3, 2014.

INCLUDE WHEN CITING Published online January 9, 2015; DOI: 10.3171/2014.10.PEDS14292.

DISCLOSURE The authors report no conflict of interest concerning the materials or methods used in this study or the findings specified in this paper. 


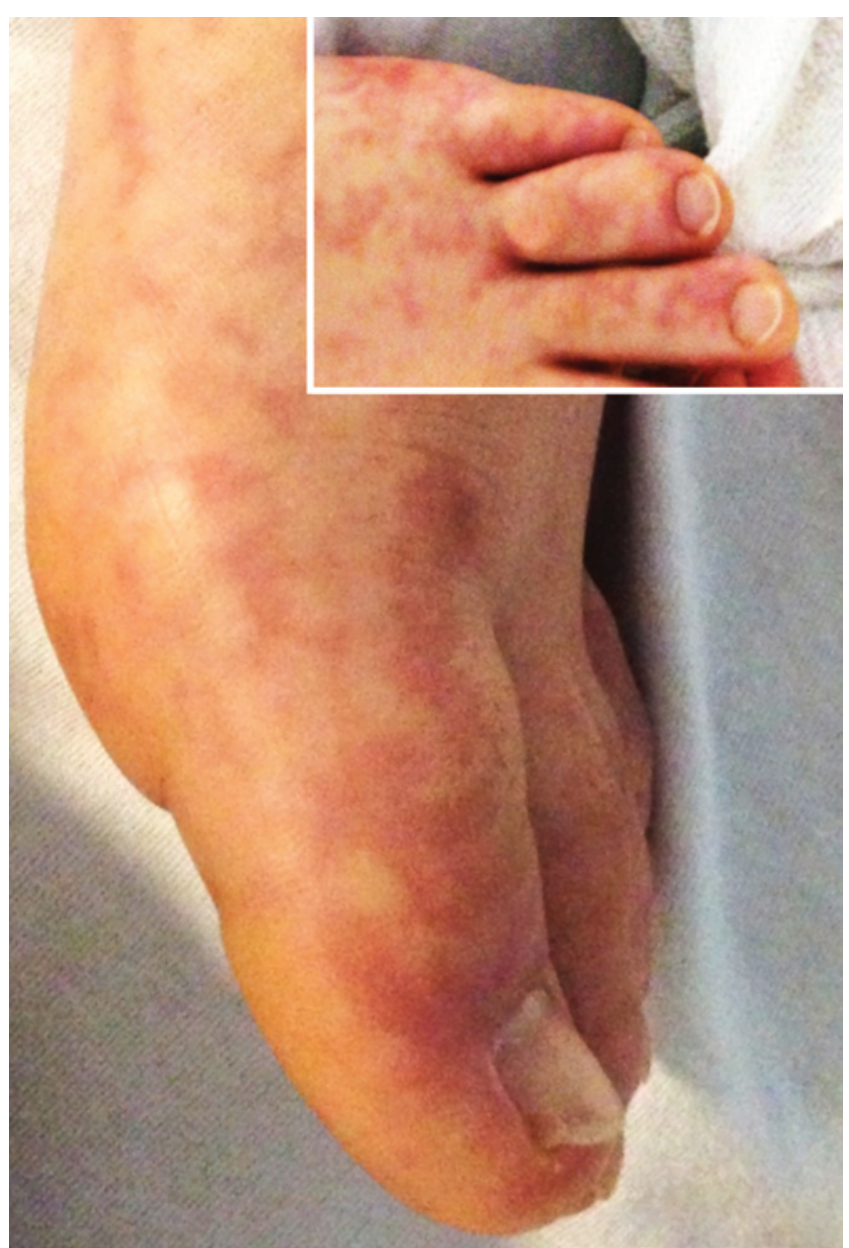

FIG. 1. Photographs showing mottled erythematous lesions in the feet consistent with livedo reticularis, which is the cutaneous manifestation of peripheral emboli from atrial myxoma. Figure is available in color online only.

tery (MCA) (Fig. 2 right). In line with current guidelines for pediatric AIS, he was not eligible for intravenous (IV) recombinant tissue plasminogen activator (r-tPA) therapy due to risk for significant bleeding, and instead underwent
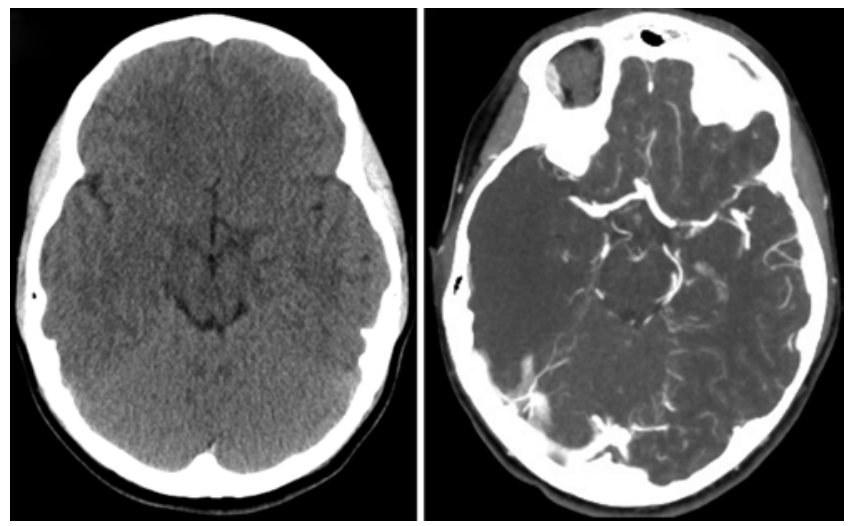

FIG. 2. Left: Axial noncontrast CT scan acquired on arrival, demonstrating early evidence of hypodense changes in the right hemisphere. Right: Subsequent CT angiogram revealing complete right MCA occlusion from a proximal $\mathrm{M}_{1}$ segment thrombus. emergency endovascular surgery for clot retrieval at 3 hours and 3 minutes after initial onset of symptoms.

\section{Endovascular Management}

A diagnostic cerebral angiogram was performed under general endotracheal anesthesia. Selective catheterization of the right internal carotid artery confirmed complete occlusion of the right $\mathrm{M}_{1}$ segment of the MCA, as well as occlusion of a fetal posterior communicating artery (PCoA) (Fig. 3).

Mechanical thrombectomy was initially attempted using the Trevo clot retrieval system (Concentric Medical, Inc.), with 3 passes in the MCA; however, only partial clot retrieval was possible, and the $\mathrm{M}_{1}$ segment remained occluded (images not shown). The thrombectomy was particularly difficult because of significant clot resistance; the retrieved portions of the clot were unusual and appeared fatty, gelatinous, and friable. Complete revascularization of the proximal $\mathrm{M}_{1}$ segment with thrombectomy was achieved using the Penumbra 041 System (Penumbra, Inc.). Small distal MCA emboli and fetal PCoA emboli were noted after restoration of flow in the proximal MCA (Fig. 4), and the Penumbra System 026 was used to revascularize the distal branches of the MCA as well as the fetal PCoA. In summary, we achieved complete revascularization of the $\mathrm{M}_{1}$ segment of the MCA, the fetal PCoA, and approximately $90 \%-95 \%$ of all distal branches; only 1 small distal MCA branch remained stagnant at the end of the procedure and was in a territory no longer amenable to thrombectomy (Fig. 5).

\section{Postoperative Course and Follow-Up}

In the postoperative period the patient was noted to have some improvement, with movement in the left upper extremity by withdrawing to painful stimuli, but initially no movement was appreciated in the left lower extremity. As part of his stroke workup, the patient was started on aspirin, and echocardiography was performed on hospital Day 2 , which revealed a $4 \times 3-\mathrm{cm}$, pedunculated, raggededged, mobile mass attached to the lower one-third of the left side of the atrial septum, prolapsing into and across the mitral valve. The cardiac surgeons evaluated the patient for this large left atrial mass and determined that it was consistent with a myxoma; he was taken to the OR urgently for

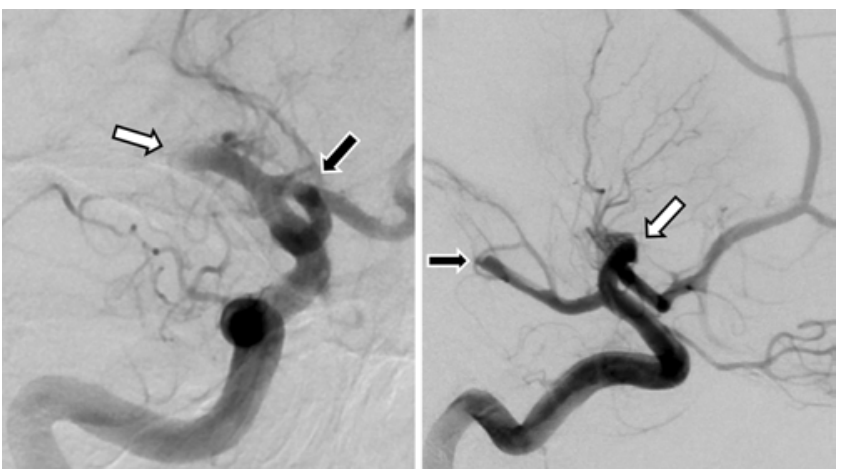

FIG. 3. Pretreatment cerebral angiography with anteroposterior (AP) (left) and lateral (right) projections demonstrating right proximal MCA (white arrows) and fetal PCoA (black arrows) occlusions. 


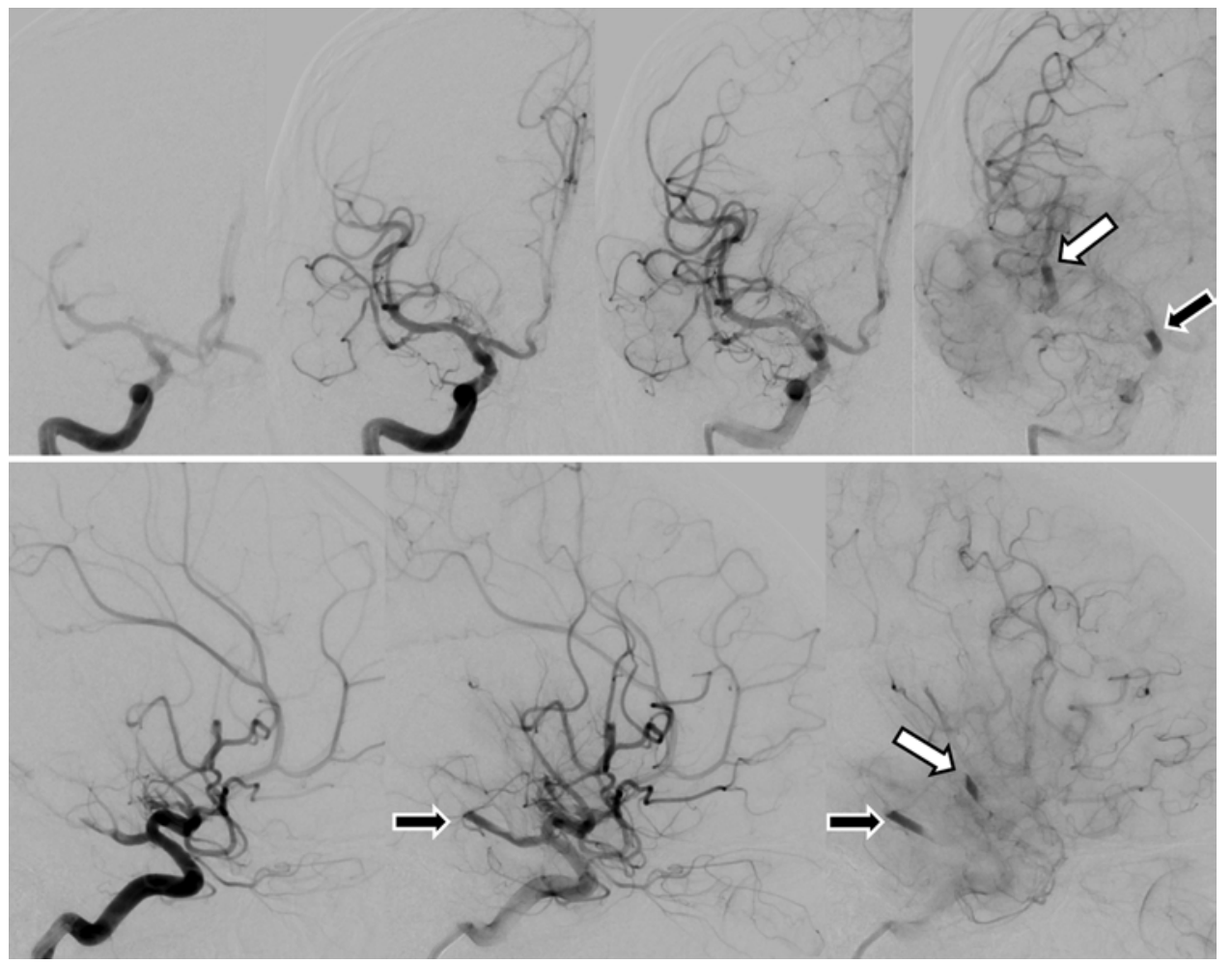

FIG. 4. Angiography with AP (upper) and lateral (lower) projections demonstrating successful recanalization of the proximal $M_{1}$ segment after mechanical thrombectomy. Small distal emboli were noted in the distal MCA segment (white arrows) and right fetal PCoA (black arrows). Images represent sequential frames.

removal of the mass to prevent additional embolic events. The specimen was sent to the pathology laboratory, which confirmed the diagnosis of atrial myxoma (Fig. 6).

By hospital Day 3, the patient had significant improvement in his left lower-extremity function and modest improvement in the left facial droop. He had continued improvement over the next week and was ambulatory by hospital Day 6. By hospital Day 9, the patient's NIHSS score had been reduced to a 7 , and he regained significant strength of 4 to $4+/ 5$ on the left side, with some apraxia. $\mathrm{He}$ was also functionally independent, with a modified Rankin Scale score of 1, and was discharged the following day for inpatient rehabilitation.

\section{Discussion}

Primary cardiac tumors are extremely rare in the pediatric population, with a prevalence of $0.0017-0.28$ in autopsy series. ${ }^{15,17}$ Although atrial myxomas are only the third most common form of cardiac tumors in children, these are of particular interest due to their autosomal dominant inheritance pattern and potential to generate AIS. ${ }^{3,18}$ Similar to our patient, a number of previous case reports indicate that AIS and neurological deficits secondary to embolic occlusion are the most common complications of atrial myxoma. ${ }^{1,6}$ In addition, as seen during the thrombectomy of our patient, emboli secondary to atrial myxoma are particularly problematic due to their friable, gelatinous, and/or villous composition, which may impede optimal response to traditional embolic treatments. ${ }^{7,14}$

While there are clear guidelines for the treatment of stroke in adults, several barriers have prevented the development of stroke guidelines in the pediatric population. Primarily, the low incidence of stroke in children delays diagnosis and prevents clinical trials that address effective treatment. ${ }^{2}$ Contrary to adult guidelines for AIS, there are no recommendations for IV r-tPA in the pediatric setting. The American College of Chest Physicians recommends anticoagulant therapy with low-molecular-weight heparin or vitamin $\mathrm{K}$ antagonist for 3 months in children suffering from AIS of cardioembolic origin. ${ }^{11,16}$

Given the lack of approved therapy for the treatment of thromboembolic stroke in pediatric patients, more studies are necessary to determine the most effective treatments of stroke in the pediatric population. Although the Thrombolysis in Pediatric Stroke (TIPS) trial was designed to determine the efficacy of IV r-tPA in children, this modality may be ineffective in patients with stroke-related atrial my xoma because the course of presentation is often deceiving, extending time to diagnosis outside the therapeutic window. Atrial myxomas are also associated with aneurysms, a contraindication to IV r-tPA and, if the myxoma itself embolizes, it is not treatable by thrombolysis. ${ }^{9,10}$ Together, these potential complications support mechanical thrombectomy as an alternative in the treatment of cerebral embolism secondary to atrial myxoma.

Mechanical thrombectomy has been described in a number of pediatric case reports as treatment for occlusive AIS. ${ }^{8}$ In previously documented cases in the literature, ${ }^{19}$ pediatric patients were treated within a mean time of 17.6 hours (range 3-44 hours) with a variety of techniques and devices. In cases of documented complete recanalization 

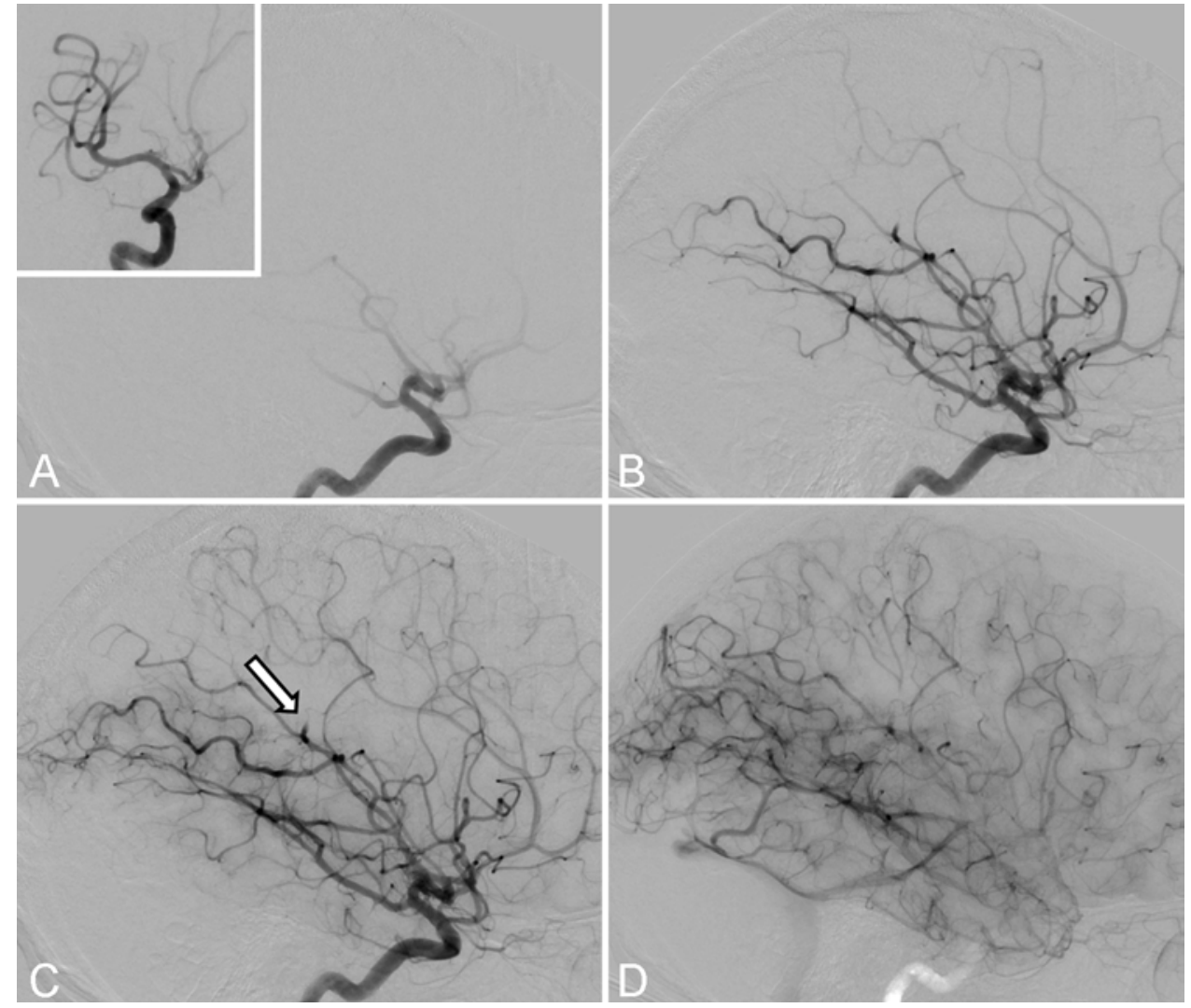

FIG. 5. Final cerebral angiogram in the lateral projection after completion of mechanical thrombectomies targeting the remaining emboli. We achieved complete revascularization of the right proximal $M_{1}$ segment, the right fetal $P C o A$, and approximately $90 \%-95 \%$ of all distal right MCA branches. There was only 1 small distal MCA branch (white arrow) that remained stagnant and was in a distal territory no longer amenable to thrombectomy. Images represent sequential frames. Inset is of a representative AP projection.

following successful mechanical thrombectomy (8 of 15 reported cases), there has been a trend toward favoring the use of the Penumbra device (50\%; 4 of 8 cases) over that of the Solitaire device (25\%; 2 of 8 cases), although there is still no consensus to date. ${ }^{8,19}$
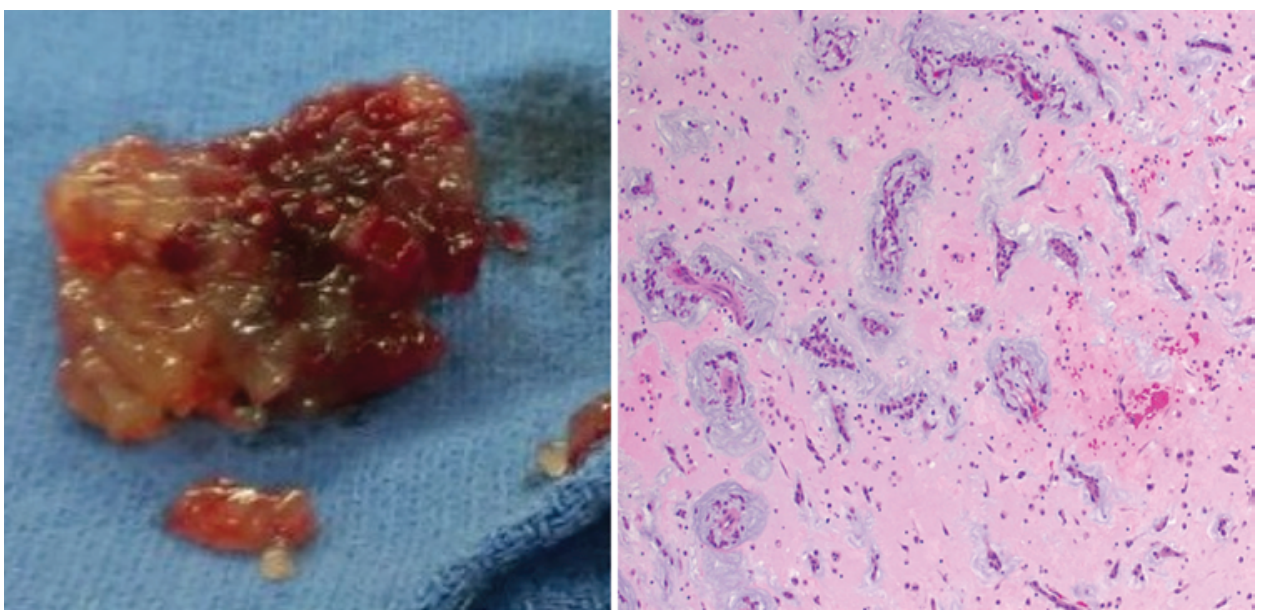

FIG. 6. Left: Photograph showing gross pathology of the $4 \times 3 \times 2.8-\mathrm{cm}$ atrial myxoma retrieved at surgery. The tumor is attached to myocardium by a short stalk, and has a gelatinous and friable consistency similar to the material encountered during mechanical thrombectomy. Right: Photomicrograph of a specimen used for histopathological investigation demonstrating spindle and stellate myxoma cells in an abundant edematous and myxoid matrix. The myxoma cells form strands and rings around capillaries in a characteristic pattern. $\mathrm{H} \& \mathrm{E}$, original magnification $\times 20$. Figure is available in color online only. 
ing with left MCA syndrome. Similar to our case, GarciaPtacek et al. ${ }^{7}$ describe clot resistance requiring multiple passes for complete removal during thrombectomy. In addition, in the adult cases variability in success and subsequent clinical outcome have been described, further highlighting the unique complications posed by atrial myxoma emboli secondary to clot heterogeneity. Lee et al. also suggest that mechanical thrombectomy may be superior to IV r-tPA in the setting of atrial myxoma emboli due to their association with microaneurysms. ${ }^{12}$ Together, prior evidence in adults and the pediatric case reported here support mechanical thrombectomy as a treatment modality for cerebral emboli secondary to atrial myxoma.

\section{Conclusions}

This case report provides support for acute mechanical thrombectomy as a safe and effective treatment for occlusive stroke secondary to pediatric atrial myxoma emboli. More studies are needed to determine the benefit of mechanical thrombectomy, particularly in the setting of atrial myxoma, in which aneurysms and heterogeneic clots may preclude the use of traditional fibrinolytic or anticoagulation approaches.

\section{References}

1. Al-Mateen M, Hood M, Trippel D, Insalaco SJ, Otto RK, Vitikainen KJ: Cerebral embolism from atrial myxoma in pediatric patients. Pediatrics 112:e162-e167, 2003

2. Amlie-Lefond C, Chan AK, Kirton A, deVeber G, Hovinga CA, Ichord R, et al: Thrombolysis in acute childhood stroke: design and challenges of the thrombolysis in pediatric stroke clinical trial. Neuroepidemiology 32:279-286, 2009

3. Becker AE: Primary heart tumors in the pediatric age group: a review of salient pathologic features relevant for clinicians. Pediatr Cardiol 21:317-323, 2000

4. deVeber GA, MacGregor D, Curtis R, Mayank S: Neurologic outcome in survivors of childhood arterial ischemic stroke and sinovenous thrombosis. J Child Neurol 15:316-324, 2000

5. Engle R, Ellis C: Pediatric stroke in the U.S.: estimates from the kids' inpatient database. J Allied Health 41:e63-e67, 2012

6. Fuchs J, Leszczyszyn D, Mathew D: Cardiac myxoma causing acute ischemic stroke in a pediatric patient and a review of literature. Pediatr Neurol 50:525-529, 2014

7. Garcia-Ptacek S, Matias-Guiu JA, Valencia-Sánchez C, Gil A, Bernal-Becerra I, De las Heras-Revilla V, et al: Mechanical endovascular treatment of acute stroke due to cardiac myxoma. J Neurointerv Surg 6:e1, 2014

8. Hu YC, Chugh C, Jeevan D, Gillick JL, Marks S, Stiefel MF: Modern endovascular treatments of occlusive pediatric acute ischemic strokes: case series and review of the literature. Childs Nerv Syst 30:937-943, 2014

9. Hung PC, Wang HS, Chou ML, Huang SC, Su WJ: Multiple cerebral aneurysms in a child with cardiac myxoma. J Formos Med Assoc 91:818-821, 1992

10. Jauch EC, Saver JL, Adams HP Jr, Bruno A, Connors JJ, Demaerschalk BM, et al: Guidelines for the early management of patients with acute ischemic stroke: a guideline for healthcare professionals from the American Heart Association/ American Stroke Association. Stroke 44:870-947, 2013

11. Lansberg MG, O'Donnell MJ, Khatri P, Lang ES, NguyenHuynh MN, Schwartz NE, et al: Antithrombotic and thrombolytic therapy for ischemic stroke: Antithrombotic Therapy and Prevention of Thrombosis, 9th ed: American College of Chest Physicians Evidence-Based Clinical Practice Guidelines. Chest 141 (2 Suppl):e601S-e636S, 2012

12. Lee VH, Connolly HM, Brown RD Jr: Central nervous system manifestations of cardiac myxoma. Arch Neurol 64:1115-1120, 2007

13. Lynch JK, Hirtz DG, DeVeber G, Nelson KB: Report of the National Institute of Neurological Disorders and Stroke workshop on perinatal and childhood stroke. Pediatrics 109:116-123, 2002

14. Markel ML, Waller BF, Armstrong WF: Cardiac myxoma. A review. Medicine (Baltimore) 66:114-125, 1987

15. McAllister HA Jr: Primary tumors of the heart and pericardium. Pathol Annu 14:325-355, 1979

16. Monagle P, Chan AK, Goldenberg NA, Ichord RN, Journeycake JM, Nowak-Göttl U, et al: Antithrombotic therapy in neonates and children: Antithrombotic Therapy and Prevention of Thrombosis, 9th ed: American College of Chest Physicians Evidence-Based Clinical Practice Guidelines. Chest 141 (2 Suppl):e737S-e801S, 2012

17. Nadas AS, Ellison RC: Cardiac tumors in infancy. Am J Cardiol 21:363-366, 1968

18. Riela AR, Roach ES: Etiology of stroke in children. J Child Neurol 8:201-220, 1993

19. Sainz de la Maza S, De Felipe A, Matute MC, Fandiño E, Méndez JC, Morillo P, et al: Acute ischemic stroke in a 12 -year-old successfully treated with mechanical thrombectomy. J Child Neurol 29:269-273, 2014

\section{Author Contributions}

Conception and design: Vega, Reavey-Cantwell. Acquisition of data: Vega, Anene-Maidoh, Grimes, Reavey-Cantwell. Analysis and interpretation of data: Vega, Chan, Grimes, ReaveyCantwell. Drafting the article: Vega, Chan, Anene-Maidoh, Reavey-Cantwell. Critically revising the article: Vega, Chan, Anene-Maidoh, Reavey-Cantwell. Reviewed submitted version of manuscript: all authors. Approved the final version of the manuscript on behalf of all authors: Vega. Administrative/ technical/material support: Reavey-Cantwell. Study supervision: Reavey-Cantwell.

\section{Correspondence}

Rafael A. Vega, Department of Neurosurgery, Children's Hospital of Richmond, Virginia Commonwealth University, 417 N. 11th St., 6th Fl., Richmond, VA 23298-0631. email: ravega@ mcvh-vcu.edu. 